\title{
Human Aids to Machines*
}

\section{Man's Productive Capacity, Past and Present \\ By A. Russell Bond, Managing Editor Scientific American}

RECENTLY one of my associates on the staff of THE Scientific American, Mr. J. M. Bird, undertook to investigate the productive capacity of man in the present day as compared to his capacity a hundred and fifty years ago-or before the age of machinery. He found the task a very complicated one, but he arrived at certain conclusions, from which I shall quote at some length, as they have a distinct bearing on the subject as announced in the program. His method of procedure was to investigate various occupations of former times, find out as best he could the quantity of product that a man could turn out in a given time, and compare this with the work of a man today who employs up-to-date machinery for the same class of product. He found that the type of machine containing the greatest labor-saving potentiality is the multiple unit one. "Here each unit replaces a single man worker, for the units are so combined that many of them are handled from a single control by a single operator. The units may work faster than the man but this is an incident. The inherent advantage lies in the fact that here we have actual multiplication of the operative's hands. The example par excellence is the spinning wheel. Here one girl, in charge of several thousand spindles, will turn out from 10 to 12 thousand times as much cotton yarn as her great grand mother's mother could produce on the spinning wheel with its single spindle. In one type of mule the exact figures are 820,000 yards per hour, against 75 . Knitting and weaving machines are not so effective, because they require more attention from the operator, who, accordingly, does not care for so many of them. Even so, the ordinary power loom increases the individua output of from 40 yards per week to well above 3,000 a factor of 75 or more."

In this way he went through the various types of multiple unit machines, not only in the textile industries, but in other lines of work as well, and finally arrived at the conclusion that from 75 to 100 seemed to represent a very fair general average for a produc tive factor of the multiple unit machine.

"The second fundamental type of machine is the one which requires an operative for each unit, and here the economy depends solely upon speeding up the work It is in the book and magazine factory that we find the most consistent reliance placed in the single unit mechanism. The linotype, for instance, does the work of from four to eight hand compositors, and this is a fair average. On the old Ben Franklin press, requiring inking, insertion of paper, screwing down and screwing up again, and removal of the sheet, it was hardly up again, and removal of the sheet, it was hardy
possible to strike off more than 30 impressions per hour of four pages each. The latest flat-bed press has a practical capacity of 1,400 impressions per hour, and printing 16 pages at each stroke, we get 22,400 pages per hour, against 120 by hand. Under union conditions, three men are required for two presses; so, in tions, three men are required for two presses; so,
practice, we get a factor here of 120 . But an automatic feeder is now on the market which makes it easily possible, as far as the machinery itself is con cerned, for one man to run two presses. On this ground, without reference to extrinsic restrictions, it will be seen that the printing machinery is capable of multiplying the book printer's capacity by 360 . In the bindery we find the gathering machine collecting the pages of five volumes while a girl is doing one. The case-making machine does a rather complicated job of cutting, fitting and pasting, and shows a factor of at least 10. The machine which puts the book in its jacket imitates closely the hand-worker's technic and attains a factor of somewhat less than 3."

Turning from this to other classes of work, we finally arrive at the figure 10 as a fair average factor for the single unit machine in all fields.

"There are other machines that so revolutionize the way of doing things that there can be no comparison with the hand-worker sufficiently close to justify either of the preceding classifications. One such type is that which receives the raw material in bulk and delivers the finished article-more often than not counted and packed. The web press for newspaper printing will turn huge cylinders of paper into finished news sheets at the rate of 288,000 eight-page papers per hour. Ten operatives are employed on the machine

*A paper dellvered before the Soclety of Industrial Engl*A paper delivered before the
neers at Chlcago, March 28, 1918. which gives us 230,400 pages per man per hour. This is something like 8,000 times as fast as Benjamin Franklin could have done the job." In the case of the web press the machine is really a factory in itself; on the other hand, we must consider many of our large rials flow in a steady stream at one end and emerge at the shipping platform as the finished product. Automobiles, shoes, canned goods, etc., are some of the commodities whose mode of production is known to follow this plan." The only way to ärrive at a comparison is "to divide the total output out of the factory by the number of employees and compare the output per man, thus found, with that of a single hand-worker. ${ }^{*} *^{*}$ When we make anything so complicated and heterogeneous as an internal combustion engine, or a pair of shoes, we inevitably find many operations that must be done by the slowest of machines or even by hand. When these form a governing factor in the output, we must either slow down the faster items to the pace of these slower ones or employ a dispruportionate number of men at the slow jobs." Another complication is the fact that when a shoe maker makes a pair of shoes, "every second of his time spent in the work goes to the advancement of the job in hand, while in a big factory there may be hundreds of workers who never handle any part of the finished product. $* * *^{*}$ Again, a shoemaker buys many
small parts, such as eyelets, laces, etc., which, in a big factory, are worked up in the raw."

Considering all these complications, of which I have enumerated only a few, the conclusion is finally reached that the average factor of assembled goods would be about five.

Another class of machinery considered is that which affects economy "by taking a bigger bite of work than a man could handle. A good-sized bucket dredge, for instance, may multiply the efficiency of the worker by a hundred. The lifting and loading magnet moves 90 tons of metal per man per hour, against $1 \frac{1}{2}$ tons by a longshoreman in the old way. * * * The huge loading and unloading machines of the Great Lakes may replace almost any number of men from a hundred up; the bigger the job, the bigger the saving." For motor transportation 5 is the factor arrived at, while freight transportation by rail shows a factor of about 25.

The final conclusion from all these figures is that a man today is productively worth ten men of the period of 1750 to 1800 .

Undoubtedly machinery has done wonders for man as a whole, but what I wish to consider in this paper is the relation between the machine and the man who operates the machine. The word "man" is used in the broad sense, including women, of course. When the primitive man first took up a stick of wood to defend himself against the beast, he was making use of a machine element; and this application of the lever certainly was an aid to the man. Gradually, very gradually at first, he began to develop other uses of this machine element and to acquire knowledge of them into machines that were increasingly useful. He began to use the powers of nature to drive the machine. The machine began to do the greater share of the work, until the relation between the man and the the help of the man.

Certainly a power-driven machine can hardly be classed as a mere aid to man; the man and machine do a certain work together, but they are not yoked together. The machine does the hauling and the man many machines that are driven by human power. The machine actually does the work. It takes the energy furnished by the operator, multiplying it either in speed or in power, or otherwise utilizing it in a far more efficient way than a man could himself. And so we have certainly come to the age in which we ean truthfully state that the machines are our workers and the operators are the directors of the machines. I do not like the word "labor," as applied to the work of man in the industries. It always seems to indicate a great muscular effort and wearisome toil. While this may be true of many operations, we are rapidly advancing to the point in which the operator has less and less use for his muscles and more and more use for his brain. I think that the industrial engibeer has a mission to perform in emphasizing this point for our industrial classes showing the operatives that machinery takes them out of the laboring class and makes them directors of machinery.

I should like to see the name "Labor Union" changed to "Director's Union." Please understand that I have not a word to say against the members of Labor Unions or their organization. They have dignified the word labor so that it has lost much of its original significance; and yet it did originally mean wearisome work and great muscular effort. But now we are gradually getting away from such toil and have entered a new era-an era in which brains count for more than muscle.

Man has developed marvellous mechanical contrivances. We have machines that can do almost anything that a man can do. We have machines that can see; machines that will keep watch of the smokestack of a steamer, and, if dense smoke comes out of the stack, will notify the engineer below, so that he can attend to the proper firing of his furnace. There are machines that can hear-that can take down a speech and record it on a wax cylinder, and which can then reproduce this speech exactly as it was given to them; machines that listen for the throbbing of the submarine's engines; railroad signals that respond to the blast of a locomotive whistle. There are machines that can feel the weight of a fly's wing; machines that can sense the tremble of the earth, five thousand miles away; machines that respond to the heat of celestial bodies trillions of miles distant; machines that can count the very atoms in the lightest of gases. On the other hand, we have machines that can lift stupendous masses of metal with little apparent effort; that can pick up a loaded coal car and pour out its contents; that can exert a pressure of ten million pounds on a test column.

All the senses of man have their counterpart in machines except possibly those of taste and smell, which are really chemical reactions; as I am using the term "machine" in the broadest sense I am not at all sure that there may not be certain instruments which will respond to the acidity or non-acidity of various solutions or to other chemical reactions that correspond to taste in the human machine. There is a mechanical contrivance which, if attached to the gas jet, will smell the gas when it has been blown out by Mr. John Hayseed, and bring into operation a mechanism that will light the gas again. There are machines that seem almost possessed with human intelligence. One clever inventor recently produced a mechanism that could remember and forget, although he never put the apparatus to any practical application. His purpose was merely to show that memory could be reproduced mechanically. This machine, if subjected to a certain reaction, would respond to that reaction for an hour, or for a day, or for any length of time to which it was adjusted, after which it would forget what it was supposed to do, and do the wrong thing, or fail to function altogether. More human in character, certainly of more service, are the machines which will solve mathematical problems. Not only those which will add and subtract, multiply and divide, but the complicated machines which will solve problems in calculus and higher mathematics-the in tegrator, for instance, which will solve problems that cannot be worked out mathematically. The tide re corder in Washington will perform mathematical calculations that a hundred computors could work out in the same time.

But wonderful as all these machines are, not one of them is endowed with real intelligence. Man can produce a machine that will play chess, but the machine cannot do its own thinking; it will only do what t has been designed to do. It will react to the various conditions to which it may be subjected, but it has no will of its own and no power of thought. No matter how far we may advance in the development of machinery we shall always come up against this barrier-the impossibility of producing brains. The most perfect of machines is useless without an intelligent operator. In the industries of the future, no matte how far they are advanced, operators will be indis- 
pensable; they will be required for their directive intelligence rather than their muscular power. Instead, therefore, of bewailing the fact, as men frequently do even in these enlightened days, that machines are re placing men we must look upon the subject from broader point of view and realize that machines are demanding men, and that they are elevating man to a higher plane.

One of the sad features of the dreadful war we are now engaged in will be the return from the fighting front of men who have been disabled or crippled so that they will be unfit for the work that they used to perform. This is a subject that is to be taken up at length tomorrow afternoon and evening; and while I do not wish to anticipate anything that may be said

\section{The Energy Required to Produce Rain*} By J. Patterson

Meteorology and geology, in their broader aspects treat of the two fundamental subjects that make lif possible on the globe. While the soil may make life impossible in certain regions, it is a fact that in most cases the necessary character of the soil to support life is almost entirely conditioned on the climate, and it is chiefly the climate that determines the characte of the life in any region. This, then, is a most impor tant subject for investigation.

Meteorology, as a science, is very young, perhaps some would say that it has not yet arrived at the stage when it can be called an exact science, but it is progressing. As a branch of human knowledge, however it is probably the oldest in the worla, going back to the advent of man in the world. Primitive man was chietly engaged in agriculture and hunting, and, as such, would soon become familiar with the broade features of the climate, and, as an observer of Nature, he would be an observer of the weather, in order to protect himself against it or profit by it, rather than with any desire or thought as to the causes of the various kinds of weather that he experienced. In course of time he soon acquired considerable local weather knowledge, and this, in turn, became crystallized into proverbs which had all the finality of absoluteness about them. With the rise of the priestly caste, the weather was linked on to the constellations, and human and weather astrology went hand in hand. In fact, in Babylonian culture astrometeorology formed part of their religion. This is the source of much of the popular weather wisdom that still survives, and it is applied independent of the locality to which it originally referred. Now, belief in astrology in our country has practically died out as far as it refers to human beings, but it is not so in regard to weather astrol ogy, for all long-range forecasting that depends on the stars is simply astrology. It is one of the charac teristics of human nature that the superstitions and weather proverbs learned in childhood survive through most of ane's adult life. One other peculiar feature of human nature is the regard in which these socalled prophets are held. When they have attained a certain notoriety they are considered infallible, apparently because only the chance successful guesses are remembered and the rest are forgotten. The weather proverbs and much of the forecasting by stars arose in an age when all phenomena were a mystery and in many cases produced by a god of good or evil repute That this nonsense should still survive is, no doubt, due to the fact that, to the great mass of the people, the weather phenomena are still a mystery. We are highly amused at the absurd stories of primitive people in regard to the creation, etc.; but, considering thei primitive character, should we consider these storie any more absurd than the weather proverbs and simi. lar nonsense among people of the intelligence of those of our own country? It does point to this, that mete orology is almost entirely neglected throughout the whole of our educational system from the kindergarte to the university. This should not be so, but it is beyond my subject for this evening. I want you to look at this from another viewpoint.

It can best be illustrated by an example. Suppose you were given the task of sprinkling an acre with water to the depth of one inch. How much work would you do? Suppose the source of the water was right at the center of the field and that the field was cir cular of radius $r$ feet. If you carried $61 / 4$ gallons, or 1 cubic $\mathrm{ft}$., each time, a simple calculation shows that you would have to travel nearly $\mathbf{1 1 0}$ miles to do it 1 acre $=43,560$ sq. $\mathrm{ft}$.

$r=17.7 \mathrm{ft}$.

*From the Journal of the Royal Astronomical Soclety of

at that time, I wish to bring out a point which has a direct bearing upon the subject before us now. It is indeed fortunate that so many of our machines have eveloped to such a point that they do practically all of the work and the operator merely directs them. Were such not the case, the future of the crippled soldier would be sad indeed; but on his return from the front he will find plenty of opportunity for usefulness as a machine director-I like the word "director" even better than operative. No man will be so badly crippled, provided his power of thought is not impaired, that he cannot find a useful niche somewhere. In former times the war cripple was a liability upon the community-today the machine has turned him into an asset.

Average distance of travel $=2 / 3 \quad r \times 2=156 \mathrm{ft}$. Number of cubic feet of water $43,560 ! 12=3630$.

$$
\text { Distance travelled }-\frac{3,630 \times 156}{5,280}=110 \text { miles. }
$$

By the time you had finished you would feel, in fact you would be absolutely certain, that you had performed a great deal of work; whether useful or not is another question. Now when Nature starts her sprinkling can or turns on her hose, as she does at times, does she have to perform any work before she can do this or does she just do it without the expenditure of any energy? Let us see.

We all know that the moisture of the air is maintained by evaporation, and consequently all the moisture that is taken out of the air as rain was originally evaporated from the water on the earth's surface.

We also know that it requires heat to evaporate water, and experiment has shown that it requires as much heat to evaporate $1 \mathrm{lb}$. of water as it would require to heat 1,080 lbs. one degree. That being so, we find that it would take to evaporate 3,630 cubic $\mathrm{ft}$. of water.

$3,630 \times \frac{125}{2} \times 1,080$ B.T.U.

or expressed in work-

$=3,630 \times \frac{123}{2} \times 1,080 \times 778$

$$
33,000
$$

$=5,764,000$ H.P. per min. $=96,000$ H.P. per hour, or 4,000 H.P. per day.

This shows then that it would require a 96,000 H.P. engine working for one hour or a 4,000 H.P. engine for a whole day, transforming all its energy into the work of evaporation, to produce the vapor for one inch of rain on an acre. After the water has been evaporated it has to be raised to the level of the clouds about $4,500 \mathrm{ft}$. or 1,500 meters. The amount of work to do this is

$3,630 \times \frac{125}{2} \times \frac{4,500}{33,000}$

$=30,960$ H.P. a min. or about $=516$ H.P. an hour, or 21.5 H.P. per day.

The total amount of work required to get sufficient water to the level of the clouds to give one inch of rain on an acre is thus $5,764,000+30,960$ or $5,794,960$ H.P. That is truly a stupendous amount of work to give 1 inch of rain per acre, and now the question arises, can we find any source of energy that is capable of giving so much power year in and year out? In considering this problem, however, we do not need to consider an area of one acre, but we can take $1 \mathrm{sq} . \mathrm{cm}$. (.16 sq. in.) instead. Again let us take the precipitation for a year. In Toronto the average precipitation is about 34 in. per year, and while 40 in. is much above the average precipitation for the whole year, we can for convenience consider an average precipitatio of $40 \mathrm{in}$. or $100 \mathrm{~cm}$. over the whole world.

A depth of $100 \mathrm{~cm}$. of rain on a sq. cm. surface would give 100 grammes of water per sq. $\mathrm{cm}$. The amount of heat required to evaporate this is $100 \times 1,600$, or 60,000 calories per year, or on an average $166 \%$ calories per day; but as the globe is made up of $1 / 1$ land and $3 / 4$ water and we consider the evaporation taking place from the water surface only, it would require 220 cadories per sq. $\mathrm{cm}$. per day of heat to evaporate sufficient water to give an average rainfall of 40 in. per year over the entire land and water surface of the globe. Where then can we find this amount of heat? At Toronto, or on latitude $45^{\circ}$ approximately, the daily average for the year is 256 . The heat received per sq. $\mathrm{cm}$. on a horizontal surface at latitude $45^{\circ}$ would be approximately the average for the globe per
This, then, is the point I wish to stress. Machines The an aid to man; but they are our slaves, and they will not work without our direction. It is the duty of the industrial engineer to inspire machine directors with the dignity of their job; to make them receptive to further development of automatic machinery; to show the girl at the spinning mule, for instance, that she is an indispensable element, that she is the directing brain of a myriad-armed creature.

If the average productive capacity of a man today is ten times that of the man of yesterday it should grow tomorrow to twenty, to fifty, to a hundred. And the larger the productive factor becomes the higher will man ascend until he becomes the very soul of the machine.

q. cm. There is thus more than enough heat received from the sun to evaporate sufficient water to give an annual precipitation over the world of 40 ins.; the average precipitation is certainly much less than this. You see, then, that as far as evaporation is concerned, the heat from the sun on the water surface is suffcient to evaporate all the water that is required for rainfall and still leave a considerable margin. Next in regard to the energy required to lift the water to the level of the cloud, or 1,500 meters. To lift 1 gramme it will require an amount of energy equal to $1,500 \times 100 \times 1,000$ (approx.) $=15 \times 10^{\text {r }}$ ergs, or expressed in heat units $=$

$$
=\frac{15 \times 10^{7}}{4.2 \times 10^{7}}=4 \text { calories }
$$

approximately.

You know that when a gas is compressed it is heated, and that when it expands it is cooled, and that the cooling is independent of the time it takes to make the expansion, provided there is no way of renewing the heat. We know that as we ascend the pressure of the air gets less, and so the vapor, in rising, is cooled, and thus supplies at its own expense the energy required to lift it to the elevation. The energy required ( 4 calories) would be obtained by the air cooling $4^{\circ} \mathrm{C}$. That is less than the average fall in temperature for that height. The vapor has next to be transported to the place where it is to be deposited; but as this is brought about by the pressure distribution of the atmosphere, it is not necessary for my purpose to consider it, nor what becomes of the heat that is given out by the vapor on condensing (this is equal to the heat required to evaporate the water), except to call your attention to the immense amount of power hat is liberated for maintaining the energy of the cyclone or the agency that is producing the rainfall.

This shows, then, that it requires energy and a vast amount of it to produce rain, and that the only source that produces sufficient energy for the purpose is the sun. What I wish to emphasize strongly is this: that all the various phenomena which constitute our weather are not caused by mysterious or magical forces, nor by the position of the stars, but they are produced solely by transformations of energy from one kind to another, according to the known laws of physics. We cannot interpret all the phenomena of the weather yet, largely because we do not fully know them. In astronomy you all know how many and varied were the motions devised to account for the true motions of the heavenly bodies, and while these held sway no progress was possible in regard to discovering the laws governing them; but when their true motion was discovered it was very soon followed by the correct theory, and the enunciation of the laws of gravitation.

Before it will be possible to formulate correct laws or weather phenomena, such as cyclones, etc., it will, first of all, be necessary to know the atmosphere, especially its circulation; then when this has been discovered, it may be possible to get the correct laws which govern the weather, and it will again be sim. ply a matter of calculation to find out what the weather is going to be. The difficulties are, howerer, very great.

\section{Health of Hog Versus Health of Man}

IN one county of California the health officer receives a salary of $\$ 25$ per month, while the county veterinarian receives $\$ 125$ per month. The board of supervisors even went so far as to dispense with the health officers' services altogether, but finally reconsidered, after attention had been called to the law. None can deny that the health of domestic animals is of great importance, but is it of so much greater importance than the health of human beings?-Bulletin of the California State Board of Health. 